\title{
Small Contribution in Rural India may have Big Impact on Child Health
}

\author{
Sumita Basu ${ }^{1,2}$
}

Received: 22 November 2015 / Accepted: 28 January 2016/Published online: 2 March 2016

(C) Dr. K C Chaudhuri Foundation 2016

About ten kilometers from Rabindranath Tagore's abode Shantiniketan, in the district of Birbhum, West Bengal, is a village named Khonjonpur which is inhabited mostly by people belonging to the Santhal tribe. Their children suffer from various diseases for which they do not have access to proper medical care.

They attend a resource center named 'Suchona', run by Mr. Rahul Bose, where I have been going for the past $3 \mathrm{y}$ to conduct health camps. A total of 128 children between 6 to 16 y have been followed up during this period and their nutritional status along with general and systemic findings were recorded. During the first check up done on 2nd February 2012, $10 \%$ of the children were found to be malnourished, $13.2 \%$ had pallor, $6.25 \%$ had pyoderma, $7 \%$ had dental carries and $2.3 \%$ were found to have heart murmurs. Appropriate medications were distributed and those who required further management were taken to Kolkata.

There is a dedicated health worker who has been trained to recognise and treat minor ailments and also makes house visits. She gives out simple advice regarding hygiene and proper nutrition. Mothers of young children were advised

Sumita Basu

sumitabs@yahoo.com

1 Department of Pediatrics, Vivekananda Institute of Medical Sciences, Ramakrishna Mission Seva Pratishthan, Kolkata, West Bengal, India

2 HB-192, Sector-3, Salt Lake, Kolkata, West Bengal 700106, India

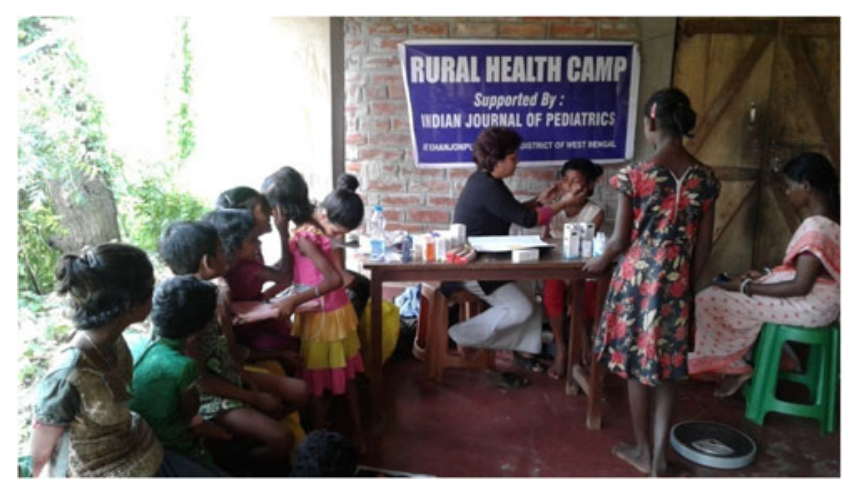

Picture 1 Health check up of children in the remote village of West Bengal

about importance of hand-washing, breastfeeding, clean drinking water, oral rehydration salts (ORS) in diarrhea, immunisation etc.

The last check up was done with financial assistance from Indian Journal of Pediatrics on 27th of September 2015 (Picture 1). On this occasion 89 children were examined, out of which malnutrition was found in $6.5 \%$, pallor in $14 \%$, pyoderma in $3.2 \%$, dental caries in $4.9 \%$ and heart murmur in $8.1 \%$. The children were better nourished and their sense of hygiene had improved.

'India Shining' campaign will hold true meaning if we can provide basic health care and education to all our children. India has failed to achieve the health targets of the Millenium Development Goals and if we pediatricians do not take it as our collective responsibility, we will fail to achieve the Sustainable Development Goals (SDG) too.

Compliance with Ethical Standards

Conflict of Interest None.

Source of Funding Indian Journal of Pediatrics. 